\title{
Noción "formal" de los derechos humanos
}

\author{
Ángel Sánchez de la Torre \\ Catedrático emérito de Filosofía del Derecho \\ de la Facultad de Derecho de la Universidad \\ Complutense de Madrid. Académico de la Real Academia \\ de Jurisprudencia y Legislación
}

Las expresiones políticas, jurídicas, ideológicas, culturales, etc., en que las nociones de "derechos humanos" aparecen, como enunciados generales o en sectores particulares, y de una u otra manera ("derechos fundamentales", "valores constitucionales") como sinónimos o como aplicaciones de ese reservorio axiológico, ocasionan gran confusionismo conceptual y a veces redundan en grandes frustraciones colectivas cuando aparecen en boca de personalidades políticas o en textos retóricos: pues se pone en juego su credibilidad o se instrumentan demagógicamente. Conviene, por tanto, rehacer un esfuerzo intelectual para fijar con cierta exactitud la índole, los objetivos, los métodos de aplicación e incluso la "fundamentación" de los derechos humanos: un estudio paradójico, puesto que se trata a su vez de valores que se constituyen en "fundamentales" respecto al ordenamiento jurídico, donde aparecen como supuestos axiomáticos que inspiran el sentido y las funciones que cada ordenamiento jurídico habría de asumir en forma de objetivos de política legislativa.

Si nos fijamos en la fundamentación de los propios derechos humanos, podremos buscar una noción "real" de los mismos, pues se deberían buscar, detrás y antes de las expresiones lingüísticas y de la presencia institucional de los derechos humanos, las fuentes primigenias a partir de los cuales hayamos fijado sus formas iniciales, las cuales a su 
vez se habrían de convertir en reglas para una exacta inteligencia de los mismos.

Mas ello no sería bastante. Una vez contemplado su proceso formativo (que ha de manifestarse en su desarrollo histórico en los países de la cultura occidental) no se ha alcanzado aún una suficiente comprensión actual de su virtualidad, de su contenido, y de su vigencia dentro de la conciencia social. Pues los derechos humanos no se despliegan singularmente en uno u otro de los sectores de la vida colectiva, sino en un conjunto de sectores abarcados simultáneamente por pretensiones y exigencias individuales, por derechos subjetivos, por situaciones en que la existencia común está organizada en determinadas instituciones administrativas y políticas, y por horizontes globalizados en que los grupos humanos pretenden superar circunstancias en que no se encuentran conformes y que deberían ser transformadas atendiendo a todos los aspectos mencionados. Cada una de las aspiraciones o exigencias manifestadas aparecen en un horizonte de totalidad, las expresiones en que tales exigencias se definen alcanzan un ámbito general que tiende a desconocer excepciones y límites, y por ello se insinúan en formas mentales que requieren la articulación global de las pretensiones singulares, así como una vigencia simultánea y complementaria de todas ellas, que deben converger de modo sistemático en la estructura conjunta del ordenamiento jurídico en cuyo seno tales postulados reciban acogida sistemática y eficacia suficiente.

La fundamentación de los derechos humanos no tendría que depender en términos absolutos, pues se trataría de una cuestión de "racionalidad metafísica", de seguir el hilo de las razones históricas que efectivamente se hayan producido en cada caso. Pero, al haberse producido la visión inicial de los propios derechos humanos dentro de una situación espacial y temporal concreta, examinar la confluencia real de estos datos es una actitud inexcusable para detectar los hitos de su propia racionalidad dentro del proceso secuencial de lo que los derechos humanos entrañan en sus propias afirmaciones. Ese conjunto de síntomas debe ser te- 
nido en cuenta y se le debe asignar a cada uno de sus elementos, por "meramente histórico" o por "meramente nominal" que aparezca, el peso y la importancia que habría de adquirir dentro de un conjunto amplio de manifestaciones fundantes. Pues el éxito de cada una de estas contingencias no puede ser alcanzado de modo separado. Es posible que haya habido razones culturales (creencias) profundísimas y sinceras que no hayan abocado a una vigencia suficiente (pues no ha sido suficientemente acogida por mecanismos políticos o por condiciones económicas propicias). Pero sí podemos detectar una presencia de datos históricos que conducen hacia una institucionalización jurídica de ideales sociales que los poderes políticos (algunas veces tras ruptura revolucionaria, casi siempre mediante una acelerada evolución interna) han acertado a asumir.

Observamos que en todos los casos en que aparecen históricamente pretensiones sociales efectivas, tendentes de transformar los ordenamientos jurídicos positivos en el sentido que cada uno de los derechos humanos enunciará en su propia denominación (igualdad, seguridad, libertad, resistencia a la opresión, solidaridad, independencia, etc.), dicha sociedad se caracteriza por ciertas cualidades:

$1^{a}$. Se trata de sociedades cuyo desarrollo económico procede de la existencia de fuertes comunicaciones con territorios próximos y con otros lejanos, permitiendo grandes intercambios de materias primas y de mercancías, pero también fuerte expansión de ciencias humanas y de tecnologías experimentales, y ocasionando grandes concentraciones humanas cuya población se ha desarraigado de sus áreas tradicionales. Las comarcas de Europa central y del Reino Unido alcanzaron esta situación desde mediados del s. XVIII.

$2^{\text {a }}$. Las conurbaciones industriales y el aumento del bienestar económico del resto del territorio, junto con el gran desarrollo de la producción de alimentos, constituyen un entorno adecuado para el progreso científico y para los intercambios entre los grandes 
sabios de la época. Éstos crean un conjunto de doctrinas humanistas que alcanzan gran difusión, a la cual concurren los regímenes políticos europeos que asumían ideales "ilustrados" dentro de sus privilegiadas estructuras de poder. A su vez las concepciones humanistas decantaban, en términos y expresiones derivados de las creencias cristianas europeas, contenidos culturales que aparecían con perfiles novedosos, a través de nuevas expresiones literarias, dotadas de la influencia que los grandes intelectuales les conferían en los diferentes ámbitos del prestigio político y social.

$3^{\text {a }}$. La obra intelectual de grandes pensadores (Montaigne, Hume, Bayle, Locke, Leibniz, Montesquieu, Rousseau, Sieyès, Kant, Paine, Condorcet, Bentham), a pesar de grandes diferencias en razón de sus actitudes individuales y de sus opciones filosóficas particulares —que para los "escépticos" actuales indicarían confusionismo conceptual cuando no ambigüedades descalificadoras-, aporta enunciados muy análogos, concepciones muy semejantes, intereses culturales prácticamente idénticos. Sus aportaciones podrían ser enmarcadas en ideas contenidas en las doctrinas religiosas tradicionales, si bien asimiladas en el pensamiento racionalista de la Ilustración, pero encaminadas a afrontar de modo característico las nuevas situaciones sociales.

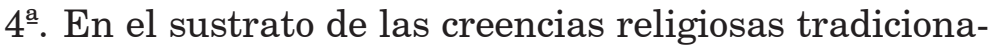
les, comunes tanto a las poblaciones europeas, con mayor o menor conocimiento dogmático, pero con profunda adhesión sentimental, y a los intelectuales mismos incluso los que pensaban ya críticamente frente a las estructuras eclesiásticas, se daba un terreno propicio para la expansión de las nuevas ideas sociales, incorporadas más en su forma de "creencias ingenuas" que en forma de razonamientos críticos complejos - propios éstos de gentes muy cultas que eran excepcionales dentro de la gran masa de las poblaciones existentes-. 
5ª . La situación creada por grandes rupturas políticas, como fueron la Independencia norteamericana y la Revolución francesa, indujo la urgencia en cristalizar las ideas religioso-humanistas en términos definidores de nuevas relaciones políticas. Ya las formulaciones de las "Declaraciones de Derechos" antecedentes tenían el objeto imprescindible de frenar el poder arbitrario y despótico de los gobiernos, y por ello fueron tenidas en cuenta como precedentes políticos que habían tenido ya efecto en este sentido, o que desde la experiencia común se estimaban necesarios. Por ejemplo la protección de los derechos individuales y patrimoniales en la Petition of Right de 1628, y el amparo judicial del Acta de Habeas corpus contra detenciones arbitrarias en 1679 habían precedido a la Declaration of Rights de 1689; y posteriormente, en Francia la doctrina de la separación de poderes en la versión de Montesquieu. Pero sus justificaciones ideológicas eran las comunes creencias religiosas: los hombres son iguales por naturaleza, han sido dotados por el Creador de derechos inalienables, los hombres establecen gobiernos para asegurar la búsqueda de la felicidad mediante el goce de tales derechos. Seguridad personal, resistencia a la opresión, libertad, propiedad eran instrumentos necesarios para el bienestar social. El ideal de "fraternidad" sería el horizonte en que estuvieran limitados los egoísmos individuales pero también los recursos del poder político, e incluso hiciera posible definir acuerdos de la "voluntad general" o de la "voluntad de todos", siguiendo el antiguo esquema aristotélico de que la "amistad" cimentaba la "comunidad política"; y en el surco agustiniano de que la "amistad" fuera "elemento potencial" de la justicia.

Esta "ocasión política" en que se discuten ampliamente las nuevas propuestas de "derechos naturales" decantan el perfil político de los textos en que se vierten tales dere- 
chos en forma de "declaraciones": del buen pueblo de Virginia, de los Estados Unidos de Norteamérica, de la Monarquía constitucional y luego República francesa, etc. Es sintomática la declaración francesa adoptada en 1789: "Declaración de los derechos del hombre y del ciudadano". La naturaleza humana parece impulsar el sentido en que cada individuo sea considerado como ciudadano, y en cuanto ciudadano se establece como contrapoder frente al Estado. La fuerza que le permite operar en este ámbito es el de la libertad. El primero de los rasgos derivados de la libertad es la igualdad, tal como se estableció en la propia Asamblea francesa al anular, en la víspera de la fecha en que se adoptaría el texto seleccionado de Declaración, el sistema feudal. Con ello vendría la liberación del régimen de las propiedades, y por tanto la posibilidad de declarar el derecho de propiedad entre los más importantes. Juntamente con la abolición de los señoríos se hace posible la unidad jurisdiccional del Estado, cuyo régimen da pleno sentido a la nueva declaración acerca de la "resistencia a la opresión".

El artículo $2^{\circ}$ de la Declaración de 1789 define el gran conjunto de los derechos humanos de este modo: "El fin de toda asociación política es la conservación de los derechos naturales e imprescriptibles del hombre. Estos derechos son la libertad, la propiedad, la seguridad y la resistencia a la opresión". En el texto de la Declaración de 1793 la expresión es diferente, en el art. 2: "Estos derechos son la igualdad, la libertad, la seguridad, la propiedad"; relación que en la Declaración de 1795 aparece en su art. 1: "Los derechos del hombre en sociedad son la libertad, la igualdad, la seguridad y la propiedad", dando la impresión de que la primacía recuperada de "la libertad" se articula con la relegación al último puesto de "la propiedad". Mientras que la noción de "resistencia a la opresión" (1789) se configura en dos artículos de 1793, que aclaran su sustitución por la noción de "seguridad" mediante dos afirmaciones: Art. 8: "La seguridad consiste en la protección ofrecida por la sociedad a cada uno de sus miembros para la conservación de su persona, de sus derechos y de sus propiedades"; 
y 9: "La ley debe proteger la libertad pública e individual contra la opresión de aquellos que gobiernan". El bando de los Montañeses no era menos crítico, sin embargo, al suavizar la antigua expresión de "resistencia a la opresión", pues el modo extremo en que la ley no se bastara para proteger contra la opresión de los gobernantes la libertad pública e individual, era nada menos que la insurrección armada: art. 35: "Cuando el gobierno viole los derechos del pueblo, la insurrección es para el pueblo y para cada porción del pueblo el más sagrado de los derechos y el más indispensable de los deberes"; y ello además de lo enunciado en el art. 27: "Todo individuo que usurpe la soberanía, debe sin más ser muerto por los hombres libres". En todo caso la "resistencia a la opresión" viene afirmada como derecho transversal de todos los ciudadanos y del pueblo en su totalidad o en parte relevante del mismo: según el art. 33 "La resistencia a la opresión es el complemente necesario (conséquence) de los otros derechos del hombre".

El Estado aparece en términos de "asociación política". No hay supremacías históricas, ni dinastías privilegiadas, ni situaciones rutinarias. La afirmación del art. 3 (1789): "El principio de toda soberanía reside esencialmente en la nación. Ninguna corporación, ningún individuo puede ejercer autoridad que no emane expresamente de ella", se afirma con el art. 25 de 1793: "La Soberanía reside en el pueblo; ella es una e indivisible, imprescriptible e inalienable". Además el Estado es producto del conjunto de aportaciones racionales de los ciudadanos, y sus criterios de organización provienen de la participación individual de los mismos: es una "asociación" (cuyo modelo jurídico pertenece al derecho privado) aunque se instala como entidad política, imaginada tal vez como resultado de los pactos roussonianos. Ello no indica, sin embargo, como se ha observado muchas veces en contraste con los derechos sociales introducidos en la versión de 1793, que se trata de una declaración ideológicamente "individualista". Otra cosa es que posteriormente se plantearan interpretaciones distintas, donde liberalismo y socialismo reclaman cierta prevalencia según unos u otros de los puntos alegados, 
acerca del matiz "individualista" o "socialista" de cada uno de los derechos proclamados. Pero esta discusión se ha referido más bien al derecho de la soberanía popular, y no tanto al de propiedad. Efectivamente, veinte años después de las Declaraciones de Derechos francesas ya habían sido eliminadas las Constituciones que las habían adoptado en muchos de los Estados europeos que las habían imitado, una vez que se impusieron políticamente, tanto en las instituciones como en las teorías políticas, los moderados criterios de la Santa Alianza. Entre 1789 y 1830 se habían sucedido once modificaciones en la propia Constitución francesa. En 1848 Antonio Rosmini menciona un folleto publicado en 1831 en Alemania, según el cual, 12 Constituciones nunca llegaron a ser puestas en vigor; 75 que habían alcanzado vigencia habían desaparecido; de las 65 que estaban vigentes en aquel momento ninguna era anterior a los últimos diecisiete años, o sea, que pertenecían ya a la época de los gobiernos moderados.

En España la Constitución de 1812 había sido derogada ya desde 1814, por obra de la brutal represión fernandina. Repuesta en 1820 fue de nuevo abolida en 1823, en medio de otra sangrienta represión. El nuevo sistema constitucional, en diversos textos fue planteado en 1834 (Estatuto Real), en 1837 (Constitución), 1845 (nueva Constitución...), etc.

Estos derechos "sociales" que se expresan en el texto francés de 1793 (subvención de subsistencia, instrucción general) atienden directamente a las necesidades sociales, no a los equilibrios políticos. Por ello no aparecen hasta en una Declaración posterior a la de 1789 . Pero están conectados con la situación social antecedente, donde ya de muchos modos tenían alguna vigencia, pero por vías diferentes a las que impone como deber (pero sin mencionar el modo de hacerlo) el texto de 1793. En todo caso, hay que subrayar que también esos derechos posteriores (derecho al trabajo, protección contra la indigencia, derecho a la instrucción) venían asignados a cada persona en cuanto hombre y en cuanto ciudadano: no a grupos o clases sociales en cuanto tales. La significación de la Asamblea de 
1789 entrañaba precisamente la disolución de "estados" y por tanto la abolición de clases sociales. $\mathrm{Y}$ el régimen de disolución de los gremios como entidades orgánicas que se encargaban de la organización del trabajo llevaba también consigo la prohibición de que se constituyeran asociaciones de trabajadores, con lo cual resulta que lo de considerar "derechos sociales" a los mencionados por el texto de 1793 es una interpolación conceptual que sólo hubiera podido tener sentido, por referirnos a la propia Francia, después de los intentos cooperativos desde 1848. El art. 21, en 1793, establecía que "Los socorros públicos son una deuda sagrada, la sociedad tiene el deber de prestar subsistencia a los ciudadanos indigentes, sea procurándoles trabajo, sea asegurándoles medios de subsistencia a quienes no pueden trabajar". Mas previene al auténtico remedio a más largo plazo, en el art. 22: "La instrucción es necesaria para todos. La sociedad debe favorecer con todo su poder el progreso de los conocimientos comunes (de la raison publique) y poner la instrucción al alcance de todos los ciudadanos".

Pero la seguridad de los derechos se articula en torno al derecho de propiedad.

Son elocuentes a este respecto los textos que acerca del derecho de propiedad contiene la Declaración de 1793: Art. 16: "El derecho de propiedad es el que pertenece a todo ciudadano de gozar y disponer a su gusto de sus bienes, de sus rentas, del fruto de su trabajo y de su laboriosidad" (industrie). Añade a este último concepto el art. 17 siguiente: "Ninguna clase de trabajo productivo, de cultivo, de comercio puede ser prohibido a la laboriosidad de los ciudadanos". Derechos que garantiza el 19: "Nadie podrá ser privado de ni del menor trozo de su propiedad sin su consentimiento" (o sea, el consentimiento que requiere un contrato libre) "excepto en supuesto de que necesidad pública legalmente constatada lo exija, y bajo condición de indemnización justa y previa".

Se trataba, por tanto, de "derechos naturales individuales", entendidos como racionales (del hombre) y como políticos (del ciudadano). La propia mente revolucionaria no 
hubiera podido otorgar dimensión social a los derechos, porque ello hubiera entrañado dar valor a las antiguas instituciones sociales cuya disolución era el principal objetivo político de la nueva situación republicana. El individuo era mirado como creador del Estado mediante su capacidad asociativa, y por ello el fin del Estado era reconocer y promover ("conservación") los derechos naturales e imprescriptibles del hombre. El individuo era, por tanto, fuente y objetivo de la actividad política. Los valores expresados en la Declaración tienen relevancia en esa dialéctica Individuo-Estado, y por ello no consideran al hombre aislado proto-roussoniano, sino al ya ciudadano. La dimensión cívica resume ambas partes, la individual y la política. Dentro de este contexto no puede suponerse que los derechos declarados sean "individualistas", aunque superficialmente pudiera decirse así (error prácticamente generalizado). La expresión "hombre y ciudadano" tiene exactamente ese alcance.

El contexto de las Declaraciones es, pues político, pero el texto es a su vez jurídico. No se requiere mencionar al individuo como sujeto de los derechos: es que todo derecho sólo puede tener como titular a un individuo. El modo de serle asignados los derechos reconocidos tiene que ser individualizado, y por ello se definen tales derechos en términos de "derechos". Los que ulteriormente se definan, además de éstos, lo serán también a título jurídico, y por tanto en texto jurídico cuyo titular sólo podría ser cada individuo, aunque su objetivo incluya cierta proyección protectora de los débiles, de los necesitados, de los enfermos, de los que anteriormente eran atendidos por la "beneficiencia pública", en instituciones municipales y en establecimientos religiosos. Al proscribirse estas actividades sociales de los eclesiásticos, y al recabar para sí el Estado las competencias municipales de asistencia, en la nueva organización local rígidamente atenida a las consignas revolucionarias, el Estado tuvo que proveer por sí mismo a aquellas demandas que ya existían en la sociedad anterior: no se trataba de esas "declaraciones de derechos sociales" que también aparecen como innovaciones revolu- 
cionarias desde una visión superficial de los hechos, si se mira exclusivamente a los discursos parlamentarios y a los nuevos textos declarativos.

Los cuatro derechos definidos en la versión de 1789 son, a primera vista, individuales los dos primeros, y políticos los dos segundos. La libertad es la expansión de los intereses personales según el procedimiento de dar cumplimiento a sus deseos y de buscar el modo de adquirir los recursos precisos para satisfacer su felicidad. La propiedad es el mecanismo en que el individuo maneja sus propios bienes, los administra, los disfruta y puede disponer de ellos cambiándolos por otros y organizando de manera estable cualquier aprovechamiento de los mismos. Ambos derechos son individuales, pero también se alberga, dentro de esa dimensión contextual en que el individuo se encuentra frente al Estado, un momento dialéctico frente a la realidad política. La libertad personal viene matizada desde el ordenamiento colectivo como "licitud": entraña modos de actuar y límites a su actuación. A su vez la propiedad personal sólo puede ejercerse, aunque siempre dependerá tal ejercicio de la voluntad del propietario, en los términos en que sus modos de actuación y sus límites vienen permitidos y autorizados por las autoridades públicas que protegen igualmente las propiedades de los demás propietarios (su derecho no es "individualista" al ser considerado el titular como "hombre y ciudadano" conjuntamente). El modo en que el Estado debe cumplir con esa finalidad de "conservación de los derechos naturales e imprescriptibles del hombre" son, frente a la libertad de cada persona ("hombre"), el respetarla dentro de los límites de la licitud; y frente a su propiedad (de cada "hombre"), la garantía del ejercicio libre de sus facultades correspondientes.

Los valores "seguridad" y "resistencia a la opresión", a su vez, se incardinan en el ámbito de las instituciones públicas, desde donde amplían su eficacia hacia las esferas de cada libertad personal.

Hay una frecuente tendencia a contraponer los valores de libertad y seguridad como si fueran dialécticamente 
contradictorios (o sea, que el crecimiento de uno incluiría la disminución del otro), cuando no son sino complementarios, cada uno en su sede. El modo de "conservar" los derechos del hombre consiste en una acción positiva del Estado. La "seguridad" no es una cualidad del individuo como es la libertad, sino cualidad de la organización política, desde la cual ésta puede cumplir su parte respecto a la "conservación" de este derecho de libertad, cuya sede es la voluntad del individuo. Lo que sucede es que la función del Estado respecto a la libertad consiste en ofrecerle seguridades. Puede hacer otras muchas cosas respecto a las libertades individuales: promoverlas, subvencionarlas, etc., sobre todo en las modernas "políticas sociales" donde se definen nuevas libertades, a través de "discriminaciones positivas", o de disposiciones en que las coyundas sexuales entre gays son legalmente consideradas "matrimonio"... Pero la única función obligatoria que, para satisfacer el derecho de libertad, incumbe al Estado, no es inventar libertades, sino darle seguridad a esas iniciativas legalmente incluidas en ese fenómeno en que se manifiesta cierta voluntad individual "del hombre y del ciudadano", a la cual, en texto de la Declaración, se la denomina "libertad".

Esta "seguridad" incluye también, no sólo los actos de libertad proyectados desde el individuo, sino también la protección de los medios que le permiten a cada individuo ejercer libremente esos mismos actos, o sea, la protección de la propiedad. A su vez esta seguridad de la propiedad no es tampoco el privilegio para el propietario, puesto que sólo sería pensable que el propietario es un individuo "privilegiado" cuando no hubiera adquirido su propiedad por el propio esfuerzo y unido al esfuerzo del grupo familiar o empresarial en cuyo trabajo participa cada miembro de la misma. Casi todos los propietarios han ganado bien sus bienes, y no los han recibido por mera fortuna sin que les haya costado nada, ni por la corrupción de amigos políticos. Pero, aparte de que el derecho de propiedad es un instrumento para lograr y multiplicar bienes de los cuales otros individuos se pueden beneficiar a través de las dife- 
rentes instituciones jurídicas previstas para tener acceso a utilidades procedentes cualquier tipo de bienes ajenos, el derecho de propiedad convierte al propietario hacia ser sujeto de una libertad que no solamente puede tomar decisiones y manifestar preferencias, sino que también dispone, a través de su propiedad, de medios y recursos para optar eficazmente por alguna de ellas, incluyendo el mejor "resistir a la opresión". Pero, sobre todo, y ésta es la auténtica y esencial "función social de la propiedad", el propietario también se siente sujeto de responsabilidad, para sí mismo y sus propios intereses, y hacia los intereses de los demás. Cualquier daño o incumplimiento de obligaciones por su parte puede ser restaurado jurídicamente sólo si el causante es "solvente", o sea, si tiene recursos "con qué responder", y ello implica el gran beneficio social que representa el hecho de que los sujetos jurídicos puedan cumplir suficientemente sus responsabilidades frente a otros individuos y frente a la sociedad, precisamente por ser solventes. Sin "derecho de propiedad" el ordenamiento jurídico no es sino un campo abierto a insolventes e irresponsables. (Sin resarcimiento, ¿de qué valen a una víctima todos los castigos impuestos al infractor o al delincuente?)

A su vez la "resistencia a la opresión", que define la seguridad de unas libertades y de unas propiedades cuyo propietario se oponga en determinado momento a algún poder público, implica una característica que debe tener este poder para que pueda servir para "conservar" los restantes derechos. Se trata del requisito, que más adelante se detallará, de una estructura del Estado atenida a la "división de los poderes", conforme a la doctrina de Montesquieu que tanto influyó en el espíritu liberal de los constituyentes. Esta expresión de "resistencia a la opresión" define el deber público de impedir las condiciones de organización pública en que un determinado poder pudiera ejercerse arbitrariamente y fuera del dogma de la primacía de la legalidad. No se trata de una reacción simbólica frente a la arbitrariedad de los tribunales, o de las órdenes de encarcelamiento despóticas, sino de un propósito 
afirmado en la vigencia de la Constitución, cuyos puntos básicos eran para ser reconocida como tal: respeto a los derechos del hombre y del ciudadano, primacía de la legalidad sobre todos los criterios de licitud e ilicitud, y división de poderes. Ahora bien, este derecho no tenía más elemento individualista que el establecerse para beneficiar a cada individuo como destinatario de una actividad del Estado. Y se ejercería como "igualdad de todos los ciudadanos ante la ley".

La "destilación" de los conceptos que se decantan en la Declaración tiene un proceso bien evidente: veamos la serie de sus fundamentos, cada uno de los cuales encapsulaba y confería su propia consistencia progresivamente a cada uno de los demás (mencionando los términos literales de la Declaración de 1789, aún reinando Luis XVI):

1) El pueblo francés;

2) La Asamblea nacional constituida;

3) Los representantes en la Asamblea (del pueblo francés);

4) Declaración solemne "expositiva" de "los" (artículo determinado, por tanto) derechos naturales, inalienables y sagrados del hombre;

5) Recordatorio de los derechos y deberes de todos los miembros del cuerpo social;

6) Método para comparar todos los actos del poder legislativo y del ejecutivo con los fines de toda institución política;

7) Fundamento en principios simples y evidentes para las reclamaciones de los ciudadanos frente al Estado;

8) Método para colaborar al mantenimiento de la Constitución;

9) Horizonte en que todos puedan buscar su felicidad;

10) Reconocimiento de efectuar esta Declaración en presencia, y solicitando la ayuda, del Ser Supremo.

Sigamos ahora con la primera afirmación declarativa: "Artículo primero. Los hombres nacen y viven libres e iguales en derechos. Las distinciones sociales no pueden tener otra explicación que la utilidad común". 
Obviamente este artículo proyecta su influencia sobre todo el texto sucesivo. Ello bastará para atender los aspectos que nos proponemos aclarar, junto con el texto del art. 3: "El. principio de toda soberanía reside esencialmente en la nación. Ninguna corporación, ningún individuo, puede ejercer autoridad que no emane expresamente de ella".

De un lado está la igual libertad de los individuos (art.1); de otro la nación como protagonista de la soberanía (art.3). Correlativamente el individuo es sujeto de todos los derechos (art.1); y toda autoridad pública procede de la soberanía nacional (art.3). Por ello todos los derechos "del hombre y del ciudadano" participan de los dos polos: "individuo" y "nación", del primero para ejercer en igualdad su libertad; del segundo para participar autorizadamente de la soberanía nacional. Ambos aspectos se resumen en la expresión de "derechos-del-hombre-y-delciudadano". Pero los derechos se consideran en el individuo en cuanto que son "naturales, inalienables e íntegros" (sagrados), y en el ciudadano en cuanto "ejerciendo autoridad expresamente emanada de la soberanía nacional".

Podremos ya afirmar que, en cuanto "humanos", los derechos humanos proceden de la naturaleza en que todo individuo es igualmente libre; mientras que en cuanto "ciudadanos", el ejercicio de los derechos procede de las designaciones (positivas) establecidas en los límites que alcanza la soberanía nacional; cuya finalidad expresamente consignada en la Declaración es —no lo olvidemos- la conservación de los derechos naturales e imprescriptibles del hombre; pues toda asociación política, incluyendo y sobre todo el Estado, depende, como consecuencia y como hecho, de la declaración constitucional de que sólo en la nación en su conjunto (histórico y territorial) reside el "principio" de toda autoridad pública. Ni siquiera la Asamblea nacional que ejerce representativamente competencias nacionales puede arrogarse una autoridad pública absoluta tronchando en un instante el proceso histórico de la nación; ni menos ejerciendo en exclusiva una representación que no incluya suficientemente la representatividad de los elementos nacionales distribuidos en la totalidad del espa- 
cio geográfico en que reside el conjunto de la población nacional. Ninguna representación pública puede apropiarse totalitariamente del poder nacional por haber excluido absolutamente alguna participación eficaz de otras aportaciones representativas también nacionales, sin partir ese principio común que es la propia nación, destruida si se la divide en cuanto raíz esencial de la soberanía unitaria del pueblo en su conjunto.

La índole de los "derechos naturales", enumerados ( $p$. ej., en 1795, art. 1) como libertad, igualdad, seguridad y propiedad, sellan la continuidad teórica entre el estado de naturaleza y la sociedad civil. Condorcet estimaba que los derechos que debieran ser asumidos explícitamente en una Declaración deberían referirse a los más inmediatos y evidentes, pero atendiendo sobre todo a aquellos que los defectos o inadecuaciones de legislaciones existentes solían mediatizar o negar. Por tanto el grado de su "necesariedad lógica" pertenece a su categoría como "derechos naturales", no a su enumeración histórica. Por ello los derechos efectivamente enumerados no son convencionales ni meramente ideológicos, sino que se han considerado insertos en el centro gravitatorio de lo entendido como "derechos naturales". De ahí que esa misma enumeración de derechos declarados no cubre todos los requisitos de ser "derechos fundamentales", puesto que si ocupan el puesto eminente en las sucesivas Declaraciones, es porque ellos mismos se fundamentan (con total necesidad racional, con total conveniencia política, y con total acreditación desde sus precedentes históricos) en la más básica y radical categoría de ser "derechos naturales". A su vez éstos anidan en el conjunto de creencias subyacentes en la cultura social, que se particularizan en la tradición clásica y cristiana de los países europeos occidentales, cuya síntesis puede enunciarse en una frase de J.-M. Trigeaud (Droits premiers, 2001), de estar orientados "hacia un saber cultural unificado en torno al hombre en cuanto persona", donde un "derecho primordial" es un universal que trasciende a sus especies, pero sin dejar de estar implicado en un núcleo de derechos primordiales que dan su aliento a los de- 
rechos establecidos, y viene presentido en una mente capaz de escuchar humildemente el soplo de lo real. Pues una mente configuradora de las libertades propias de la persona humana tiene que buscar las fuentes de su regulación equilibrada - entre individuos y grupos, entre iniciativas y seguridades-, más bien en certidumbres profundas que en proyectos ideológicos, más en comprensiones que en explicaciones, más en orientaciones que en dogmas.

Pero los derechos humanos tenían también que instalarse en unas eficacias institucionales. El diputado de la Constituyente francesa Malouet advertía, a propósito del texto que se discutía, días antes de su votación, que una Declaración de derechos podría ser útil, o insignificante, o peligrosa, según cuál fuera la Constitución que la tomara como suya. Si los derechos del hombre tienen que estar desplegados y garantizados en ella, tal Declaración, al instalarse en instrumentos legales, debe alejarse del nivel metafísico y de las definiciones abstractas que se estaban a punto de aprobar en cuanto que tenían que acercarse en el terreno que habrían de regular desde aquella inspiración. Ninguno de los derechos naturales —decía dicho diputado- puede considerarse inmodificado en cuanto se le concrete como derecho positivo. En cuanto sea legal debe ser mencionado junto a sus límites de vigencia, y añadía: "si no señaláis restricción alguna, ¿no veis que se presenta a la gente derechos no atenidos a extensión exacta, siendo así que no podrán ser utilizados sino es dentro de limitaciones justas?". De ahí que las definiciones de "derechos naturales" concretos se atuvieran muy fielmente al contenido de derechos subjetivos notoriamente reconocibles dentro del ordenamiento jurídico positivo. Así la libertad (frente al estado de esclavitud, y universalizada mediante la igualdad); la seguridad (frente a los actos de arbitrariedad de tribunales y de autoridades gubernativas), la propiedad (junto a la prohibición de expropiaciones arbitrarias y sin indemnizaciones). Razonaba por ello dicho diputado que, al haber en aquella sociedad muchos conciudadanos que en su mayoría carecían de propiedades 
valiosas, y esperaban ante todo mayores probabilidades de ganar su subsistencia mediante un trabajo asegurado, necesitarían una administración exacta y además una protección continua. Mas ello no otorgaba ningún derecho natural a los necesitados y beneficiarios, en cuanto que repercutiría globalmente hacia el conjunto del pueblo, pero no frente a otros individuos concretos. Al no poder articularse la "subvención benéfica" como derecho obligacional positivo, tampoco tendría la estructura jurídica subyacente a cualquier derecho, y así tampoco en cuanto derecho natural. Pues no se podrían declarar de una manera absoluta los principios generales de un "derecho natural", sin tener en cuenta también las modificaciones que experimentarían al ser acogidos en formas de "derecho positivo". $\mathrm{Si}$ bien la ignorancia produce muchos inconvenientes y grandes desgracias — razonaba- también los conocimientos a medias y la falsa aplicación de los principios traen el peligro de su imposible satisfacción, con su cortejo de desórdenes y de frustraciones.

Estas consideraciones llevan a pensar que una noción "formal" de los derechos humanos parte de una vigencia cultural que consiste en la creencia en el valor de la libertad humana, que contiene implícitamente dos dimensiones: la referente a ada persona de la especie humana, y la referente al medio social de la existencia humana.

En el primer aspecto, tenemos que la mente individual humana puede desarrollar una capacidad de preferir objetivos y de valorar los medios pertinentes al fin por que se haya optado, y a esto lo calificamos como "racionalidad"; y que esta capacidad le confiere a ese mismo individuo humano un valor intrínseco y propio denominado "dignidad humana".

En el segundo aspecto hallamos que la conducta humana se realiza imprescindiblemente dentro de un medio de relaciones que denominamos "sociedad", y por otro lado que la existencia humana en una sociedad requiere de ciertas organizaciones que señalen los ámbitos de decisión personal en que cada uno puede actuar sin ser impedido y sin dañar a otros; y que establezcan seguridades para que 
las reglas de organización establezcan criterios de racionalidad, bajo cuya vigencia todos puedan desarrollar sus capacidades, pero que además establezcan las condiciones precisas para que unos no se sientan irrazonablemente sometidas a la voluntad de otros.

Por ello podríamos reconocer la idoneidad de aquellas ideas que relacionan el fundamento de los derechos humanos con el valor de "dignidad intrínseca de las persona" y con el valor de "igualdad político-legal de los ciudadanos". El primero constituye el fundamento de todas las libertades individuales; y el segundo el de la seguridad colectiva. Con mayor o menor precisión engloban estas nociones la mayor parte de los textos contemporáneos de Declaraciones de Derechos humanos. Así el Preámbulo de la Declaración Universal de Derechos Humanos (1948): "Considerando que la libertad, la justicia y la paz en el mundo tienen por base el reconocimiento de la dignidad intrínseca y de los derechos iguales e inalienables de todos los miembros de la familia humana..."

Con mayor claridad en el Pacto Internacional de derechos Económicos, Sociales y Culturales (1966): "Reconociendo que estos derechos se desprenden de la dignidad inherente a la persona humana". Idéntico texto se reproduce en el Pacto Internacional de Derechos Civiles y Políticos (misma fecha). Es muy explícito el párrafo del Preámbulo del Estatuto del Consejo de Europa (1848) referente a los derechos humanos, en que supera la timidez de las mencionadas Declaraciones para insistir, con una expresiva frase, en las raíces culturales que apuntan a la autenticidad propia de la fundamentación de estos derechos: "Inconmoviblemente apegados a los valores espirituales y morales que son el patrimonio común de sus pueblos y que constituyen la fuente de los principios de libertad individual, de libertad política, y de preeminencia del Derecho, sobre los cuales se funda toda democracia verdadera...”. Europa alardea, con razón, de haber sido el vector histórico de todo lo referente a los derechos humanos (y ello define también las líneas maestras de lo que habría de ser su responsabilidad histórica en un mundo globalizado). 
En conclusión se puede apuntar una definición formal de los derechos humanos atendiendo al conjunto de los elementos que los integran tanto en el aspecto de la existencia individual como al de la organización colectiva de los seres humanos, en los términos siguientes: Derechos humanos son aquellas formas de libertad de la vida social, que acondicionan el proceso de personalización individual y de bienestar colectivo, de modo que en su ausencia no podrían conseguirse tales finalidades dentro de los modelos de comportamiento propios de una sociedad civilizada.

\section{BIBLIOGRAFÍA}

Christine Fauré, Les Déclarations des droits de l'homme de 1789. Textes. Paris 1998.

J.-M. TRigeaud, Premiers droits, Bordeaux, 2001.

J.-M. TRIGEAUd, Métaphysique et éthique au fondement du droit, Bordeaux, 1999.

J. D. VERDIN, Sieyès. La clé de la Révolution française, Paris 1988.

A. SÁNCHEZ DE LA TORRE, "Rosmini y la declaración de derechos humanos del 89", Anales de la Real Academia de Jurisprudencia y Legislación, 1990.

A. SÁncheZ DE LA ToRre, "Orden jurídico y derechos humanos", Revista General de Legislación y Jurisprudencia, 1975.

A. SÁNCHEZ DE LA ToRRe, "Los derechos del hombre y el orden jurídico", Boletín del Colegio de Abogados de Madrid, 1998.

A. SÁncheZ DE LA ToRRe, Sociología de los derechos humanos, $2^{\mathrm{a}}$ ed., 1979.

A. SÁNCHEZ DE LA TORRE, El derecho en la aventura europea de la libertad, 1988. 